\title{
Biphasic cellular adaptations and ecological implications of Alteromonas macleodii degrading a mixture of algal polysaccharides
}

\author{
Hanna Koch ${ }^{1,8} \cdot$ Alexandra Dürwald ${ }^{2,3} \cdot{\text { Thomas Schweder } \mathbb{D}^{2,3} \cdot \text { Beatriz Noriega-Ortega }^{4} \cdot \text { Silvia Vidal-Melgosa }}^{5} \cdot$ \\ Jan-Hendrik Hehemann ${ }^{5}$. Thorsten Dittmar $\mathbb{D}^{4} \cdot$ Heike M. Freese $^{6} \cdot$ Dörte Becher $^{2,7} \cdot$ Meinhard Simon ${ }^{1}$. \\ Matthias Wietz (iD ${ }^{1}$
}

Received: 9 May 2018 / Revised: 10 July 2018 / Accepted: 19 July 2018 / Published online: 16 August 2018

(c) International Society for Microbial Ecology 2018

\begin{abstract}
Algal polysaccharides are an important bacterial nutrient source and central component of marine food webs. However, cellular and ecological aspects concerning the bacterial degradation of polysaccharide mixtures, as presumably abundant in natural habitats, are poorly understood. Here, we contextualize marine polysaccharide mixtures and their bacterial utilization in several ways using the model bacterium Alteromonas macleodii 83-1, which can degrade multiple algal polysaccharides and contributes to polysaccharide degradation in the oceans. Transcriptomic, proteomic and exometabolomic profiling revealed cellular adaptations of A. macleodii 83-1 when degrading a mix of laminarin, alginate and pectin. Strain 83-1 exhibited substrate prioritization driven by catabolite repression, with initial laminarin utilization followed by simultaneous alginate/pectin utilization. This biphasic phenotype coincided with pronounced shifts in gene expression, protein abundance and metabolite secretion, mainly involving CAZymes/polysaccharide utilization loci but also other functional traits. Distinct temporal changes in exometabolome composition, including the alginate/pectin-specific secretion of pyrroloquinoline quinone, suggest that substrate-dependent adaptations influence chemical interactions within the community. The ecological relevance of cellular adaptations was underlined by molecular evidence that common marine macroalgae, in particular Saccharina and Fucus, release mixtures of alginate and pectin-like rhamnogalacturonan. Moreover, CAZyme microdiversity and the genomic predisposition towards polysaccharide mixtures among Alteromonas spp. suggest polysaccharide-related traits as an ecophysiological factor, potentially relating to distinct 'carbohydrate utilization types' with different ecological strategies. Considering the substantial primary productivity of algae on global scales, these insights contribute to the understanding of bacteria-algae interactions and the remineralization of chemically diverse polysaccharide pools, a key step in marine carbon cycling.
\end{abstract}

Electronic supplementary material The online version of this article (https://doi.org/10.1038/s41396-018-0252-4) contains supplementary material, which is available to authorized users.

Matthias Wietz

matthias.wietz@uni-oldenburg.de

1 Institute for Chemistry and Biology of the Marine Environment, University of Oldenburg, Oldenburg, Germany

2 Institute of Marine Biotechnology, Greifswald, Germany

3 Institute of Pharmacy, University of Greifswald, Greifswald, Germany

4 ICBM-MPI Bridging Group for Marine Geochemistry, University of Oldenburg, Oldenburg, Germany

\section{Introduction}

Algae constitute a major fraction of biomass in the oceans and are rich in chemically diverse polysaccharides [1, 2]. Algal polysaccharides are vital structural and storage components, whose composition can vary by species and season

5 MARUM-MPI Bridge Group for Marine Glycobiology, University of Bremen, Bremen, Germany

6 Leibniz Institute DSMZ-German Collection of Microorganisms and Cell Cultures, Braunschweig, Germany

7 Institute of Microbiology, University of Greifswald, Greifswald, Germany

8 Present address: Department of Microbiology, Radboud University Nijmegen, Nijmegen, The Netherlands 
[3]. Polysaccharides released by exudation or decay [4] are an important carbon source for heterotrophic bacteria, which hydrolyze and metabolize polymeric carbohydrates via carbohydrate-active enzymes (CAZymes) [5]. CAZymes with or without carbohydrate-binding modules (CBM) include polysaccharide lyases (PL), glycoside hydrolases $(\mathrm{GH})$, carbohydrate esterases (CE), glycosyl transferases (GT) plus a range of auxiliary enzymes [6], many having been biochemically characterized in detail [7].

Flavobacteriia are pivotal polysaccharide degraders in marine systems [8, 9], but diverse CAZyme repertoires are also found in Gammaproteobacteria [10], Verrucomicrobia [11] and Planctomycetes [12]. CAZymes are often clustered in polysaccharide utilization loci (PUL) that allow the concerted degradation from polymer to monomer [13], with up to 50 PUL for a range of substrates in some bacteria [14]. Structure and expression of PUL have been described in several marine bacteria, but only considering one substrate at a time [15-19].

Despite the insights afforded by these studies, a conceptual investigation of bacterial polysaccharide degradation should consider that marine polysaccharide pools are chemically diverse and variable mixtures [20] and that competitive access to these resources is likely facilitated by dedicated cellular adaptations. In the environment, bacterial adaptive responses to varying polysaccharide pools are reflected by temporal changes in CAZyme abundance and diversity during the succession of phytoplankton blooms $[21,22]$ that produce diverse polysaccharides [23, 24]. We hypothesize that the structuring influence of marine polysaccharide mixtures on bacterial dynamics resembles processes among human gut microbiota, including sequential substrate utilization through catabolite repression and regulatory networks [25-27], with ecological implications on cellular and community levels [28, 29]. Indeed, a recent study in marine systems revealed that sequential degradation of alginate and laminarin in Bacillus coincides with temporal regulation of the respective PUL [30]. The ecological relevance of such adaptations is highlighted by substrate-controlled regulation of hydrolytic machineries for brown/green/red algae polysaccharides in Zobellia galactanivorans [31] and sophisticated laminarin uptake systems [32].

Here, we present three complementary perspectives on polysaccharide mixtures and their utilization by marine bacteria. First, transcriptomic, proteomic and exometabolomic analyses of Alteromonas macleodii strain 83-1 growing on laminarin, alginate and pectin illuminate bacterial adaptations to polysaccharide mixtures on cellular level. Second, molecular evidence that macroalgae release polysaccharide mixtures indicates that cellular adaptations are important in the environment. Third, microdiversity of hydrolytic capacities among Alteromonas spp. suggests different ecological strategies related to polysaccharide utilization. A. macleodii strain 83-1 has been isolated from an alginate-enriched microcosm and represents an ecologically relevant model organism, as $A$. macleodii degrades the algal polysaccharides laminarin, alginate, pectin, xylan and pullulan [33], dominates polysaccharide degradation in some marine regions [34-36] and occurs globally [37]. These traits may also contribute to the close associations and metabolic interactions of $A$. macleodii with phototrophs, including diatoms [38], prymnesiophyceae [39] and cyanobacteria [40-42].

The polysaccharides investigated in the present study are chemically diverse and ecologically relevant. Laminarin, composed of $\beta$-(1-3)-glucose with $\beta-(1-6)$ branches, is the major intracellular polysaccharide of macroalgae and diatoms [43] and occurs at up to $0.5 \mathrm{mg} \mathrm{L}^{-1}$ in the North Sea [44]. Accordingly, laminarinases are found in coastal to pelagic bacteria worldwide [45, 46]. Alginate, comprising homo- or heteropolymeric blocks of $\beta$-D-mannuronate and $\alpha$-L-guluronate, can constitute $>50 \%$ of benthic and pelagic brown macroalgae [47]. The environmental importance of alginate is reflected by the occurrence of alginate lyases in various bacterial taxa [48]. Pectin, largely composed of $\alpha$ (1-4)-galacturonate, is abundant in terrestrial plants, but the presence of complex pectinolytic operons in marine bacteria [49] and up to $0.3 \mu \mathrm{M}$ galacturonate during phytoplankton blooms [50] suggest that pectinous substrates are common in marine systems as well. Due to their gelling capacities, alginate and pectin may also occur in transparent exopolymer particles [50, 51]. These particulate forms of polysaccharide mixtures are attractive microhabitats for bacteria, including A. macleodii that colonizes gels derived from macroalgae [34] and diatoms [35].

Overall, our multifaceted perspective on polysaccharide mixture utilization contributes to understanding bacterial gene regulation under substrate regimes that occur during phytoplankton blooms or macroalgae decay. Considering the substantial primary productivity of micro- and macroalgae on global scales [52, 53] and the importance of polysaccharides in biogeochemical cycles [54], these insights are relevant for carbon fluxes and bacteria-algae interactions in the oceans.

\section{Materials and methods}

\section{Cultivation and sampling regime}

All cultivations were carried out in seawater minimal medium (SWM) [55] supplemented with sterile-filtered polysaccharide mix or glucose as sole carbon sources. Polysaccharides included laminarin from Laminaria digitata (L9634; Sigma-Aldrich, St. Louis, MO), alginate from 
brown algae (A2158; Sigma-Aldrich) and apple pectin (76282; Fluka, Switzerland). For all experiments, A. macleodii $83-1$ was precultured in $\mathrm{SWM}+0.1 \%$ glucose at $20{ }^{\circ} \mathrm{C}$ with shaking at $140 \mathrm{rpm}$ for $24 \mathrm{~h}$, washed twice with sterile SWM and diluted to an optical density (OD600) of 0.1 (corresponding to approximately $8 \times 10^{7}$ colonyforming units per $\mathrm{mL}$ as determined by plating on marine agar). Main cultures were inoculated in $2 \mathrm{~L}$ Erlenmeyer flasks containing each $400 \mathrm{~mL}$ SWM (supplemented with $0.06 \%$ glucose or $0.02 \%$ of each polysaccharide to provide equal amounts of carbon source per treatment) with diluted preculture at $0.5 \%(\mathrm{v} / \mathrm{v})$ in triplicate. Cultures were incubated at $20^{\circ} \mathrm{C}$ with shaking at $140 \mathrm{rpm}$. Growth (OD600; diluted if $>0.4$ ) and substrate utilization (high-performance liquid chromatography (HPLC); see below) were determined in regular intervals. Samples for transcriptomics and proteomics were taken after 13 and $21 \mathrm{~h}$. Samples for exometabolomics were taken after 13, 21 and $36 \mathrm{~h}$ (end of the incubation). In addition, utilization of single substrates was tested in $100 \mathrm{~mL}$ Erlenmeyer flasks containing each 20 $\mathrm{mL}$ SWM supplemented with glucose, pectin or laminarin $(0.05 \%$, respectively) or methanol (0.1 and $0.3 \%)$, which were incubated as described above.

\section{Carbohydrate quantification}

At each OD measurement, subsamples of $3 \mathrm{~mL}$ were filtered through $0.22 \mu \mathrm{m}$ mixed cellulose ester filters into combusted glass vials and stored at $-20^{\circ} \mathrm{C}$ until analysis. Polysaccharide mix samples were diluted $1: 3$, chemically hydrolyzed in $1.275 \mathrm{M} \mathrm{H}_{2} \mathrm{SO}_{4}$ for $3 \mathrm{~h}$ at $100^{\circ} \mathrm{C}$ in combusted and sealed glass ampoules and neutralized with $1.75 \mathrm{M}$ calcium carbonate. Samples were diluted 1:2000 (glucose) or 1:100 (hydrolyzed polysaccharides) with MilliQ before quantification by pulsed amperometric detection [56, 57] using a Carbopac PA 1 column (Thermo Fisher, Waltham, MA). Eluents were $18 \mathrm{mM} \mathrm{NaOH}$ (for glucose/ laminarin) or $135 \mathrm{mM} \mathrm{NaOH}$ (alginate/pectin). Calibration curves were generated for all substrates, with five data points for glucose and seven for polysaccharides $\left(R^{2}>\right.$ 0.994).

\section{Genome sequencing and analysis}

The genome of $A$. macleodii 83-1 was sequenced using PacBio RSII technology (Supplementary Methods). CAZymes were identified using dbCan [58], only considering hits with $e<10^{-23}$ and $>80 \%$ query coverage. Detailed annotation of selected genes was performed using Pfam, UniprotKB, InterPro, TCBD and MEROPS databases [59-61]. For the predicted GH16 (Alt831_03772) a structure-based sequence alignment was done using the ENDscript server with default parameters [62]. ZgLamA
(PDBid 4BQ1) from Zobellia galactanivorans [63] was used to guide the alignment, followed by alignment with biochemically characterized GH16 $\beta$-1,3-glucanases (CAZY accession numbers AAC25554.2, AAC69707.1, ADN02324.1 and AAD35118.1) [6].

\section{Transcriptomics}

At each sampling point, two $5 \mathrm{~mL}$ subsamples from each replicate were centrifuged for $3 \mathrm{~min}$ at $8000 \times g$ at room temperature (RT). Cell pellets were immediately flashfrozen in liquid nitrogen and stored at $-80{ }^{\circ} \mathrm{C}$ until RNA extraction. Total nucleic acids were extracted from one subsample per replicate using the MasterPure RNA purification kit (Epicentre, Madison, WI). DNA digestion using the Turbo DNA-free Kit (Thermo Fisher) was confirmed by 16S rRNA gene PCR. RNA was quantified using the Qubit RNA BR Assay Kit (Thermo Fisher) and stored at $-80{ }^{\circ} \mathrm{C}$ before shipping on dry ice to the Earlham Institute (http://www.earlham.ac.uk; Norwich, UK) for sequencing. Library preparation, quality control, sequencing and bioinformatic analysis were done following standard procedures (Supplementary Methods). Differential expression analysis of quality-checked Illumina reads as mean of three biological replicates is reported in Table S1. Changes of $\geq 2 \log 2$ fold and an adjusted $P$ value of $<0.001$ calculated using DESeq2 [64] were considered significant.

\section{Proteomics}

At each sampling point, a $20 \mathrm{~mL}$ subsample from each replicate was centrifuged for $5 \mathrm{~min}$ at $6500 \times \mathrm{g}$ at $\mathrm{RT}$. Extracellular proteins in the supernatant were processed with StrataClean resin (Agilent, Santa Clara, CA). Cell pellets were washed with phosphate-buffered saline, centrifuged again, immediately flash-frozen in liquid nitrogen and stored at $-80{ }^{\circ} \mathrm{C}$ until analysis (Supplementary Methods). Briefly, extracted proteins were separated by sodium dodecyl sulfate-polyacrylamide gel electrophoresis, obtained peptide fractions digested using trypsin and separated via liquid chromatography. Protein abundances determined by tandem mass spectrometry (MS/MS) were semi-quantified using calculated normalized spectral abundance factor (\%NSAF) values [65].

\section{Exometabolomics}

At each sampling point, a $20 \mathrm{~mL}$ subsample from each replicate was centrifuged for $20 \mathrm{~min}$ at $3500 \times g$ at $4{ }^{\circ} \mathrm{C}$. In addition, three sterile media blanks per substrate regime were incubated and processed in the same manner. Exometabolites were purified from supernatants using solid-phase cartridges containing modified styrene-divinylbenzene polymer sorbents 

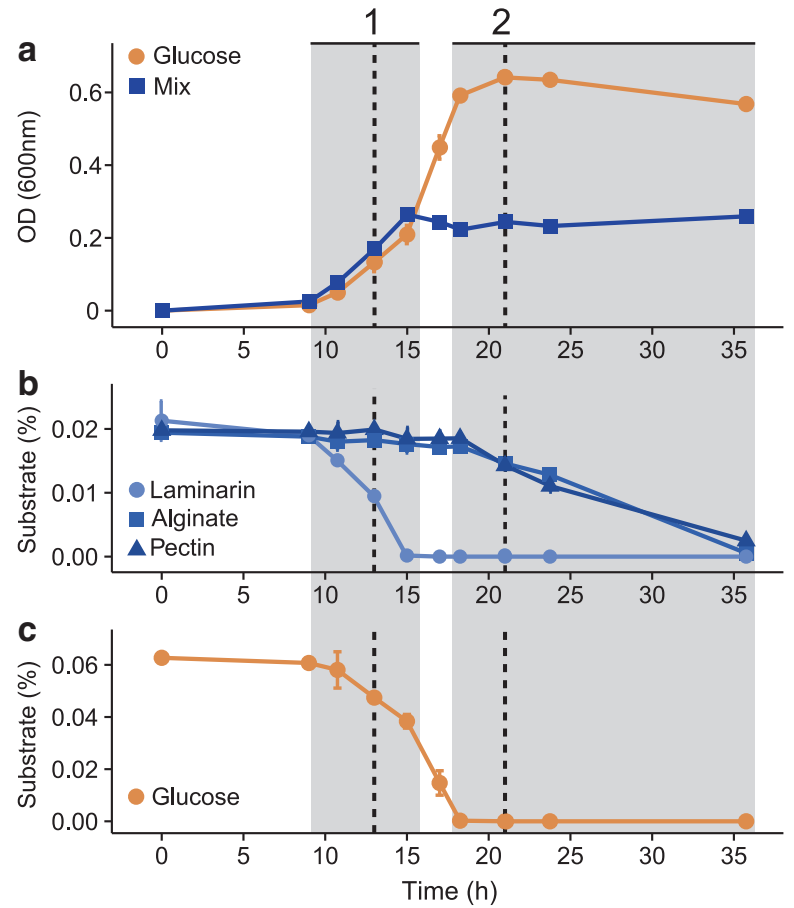

Fig. 1 Growth and substrate utilization. Biphasic phenotype of Alteromonas macleodii 83-1 (a) and utilization of polysaccharide mix (b) and glucose (c) based on three biological replicates \pm standard deviation. Both phases (shaded) were characterized using transcriptomics, proteomics and exometabolomics at the time points indicated

[66] and analyzed by ultrahigh resolution mass spectrometry [67] (Supplementary Methods). Briefly, extracted exometabolites were analyzed on a $15 \mathrm{~T}$ Solarix Fourier transform ion cyclotron resonance mass spectrometer (FT-ICR-MS) coupled to electrospray ionization (Bruker, Germany) in negative mode. Two technical replicates per biological replicate were measured, only considering peaks detected in both runs. Furthermore, obtained spectra were calibrated and denoised using strict procedures to ensure that only bacterial metabolites were evaluated.

\section{Carbohydrate microarrays of macroalgal exudates}

Fresh macroalgal specimens were collected from rocky tidal areas on the Isle of Helgoland (North Sea) in June 2017. Algae were placed inside dialysis devices with $3.5-5 \mathrm{kDa}$ membranes (Float-A-Lyzer G2; SpectrumLabs, Rancho Domingo, CA). Devices were filled with $10 \mathrm{~mL}$ ambient seawater and placed in sterile-filtered seawater for 6 days in the dark. Each $5 \mathrm{~mL}$ of dialyzed samples was filtered through $0.2 \mu \mathrm{m}$ Acrodisc filters (Pall, Port Washington, NY) into combusted HPLC vials and stored at $4{ }^{\circ} \mathrm{C}$. Samples were printed as microarrays in triplicate and probed with 28 carbohydrate-specific probes [68] (Supplementary Methods).

\section{Comparative genomics}

Alteromonas draft genomes assembled from metagenomes were annotated using Prokka [69]. We furthermore included 33 complete genomes from Alteromonas isolates [70-73] deposited at the Integrated Microbial Genomes (IMG) database [74]. CAZymes were classified using the CAZY database [6] and dbCan [58], only considering hits with $e<$ $10^{-23}$ and $>80 \%$ query coverage. Syntenic PUL were identified using MultiGeneBLAST [75], only considering hits with $>50 \%$ amino acid identity and $>70 \%$ query coverage. For taxonomic comparisons, amino acid sequences of 20 core genes identified using BPGA [76] were aligned using muscle [77]. A phylogenetic tree was constructed using FastTree with 1000 replications [78] implemented on CIPRES [79]. Homologs of A. macleodii 83-1 genes putatively involved in catabolite repression were searched against marine metatranscriptomes deposited at IMG, only considering hits with $>90 \%$ amino acid identity and $>60 \%$ query coverage.

\section{Results and discussion}

A. macleodii 83-1 cultivated on a mixture of laminarin, alginate and pectin showed a biphasic phenotype relating to polysaccharide preferences (Fig. 1). Initial exponential growth during laminarin utilization until its complete consumption (phase M1) was followed by simultaneous utilization of alginate and pectin, but without net growth (phase M2).

Phases M1 and M2 coincided with major temporal shifts in gene expression, protein abundance and metabolite secretion (Figs 2-4; S1-2), involving 1-2 PUL per polysaccharide plus additional gene clusters (Table S3). These adaptations match those of pivotal polysaccharide degraders such as Zobellia galactanivorans [31], substantiating the relevance of $A$. macleodii for the remineralization of algal polysaccharides $[33,34]$. The prioritization of laminarin over alginate was diametric to Bacillus weihaiensis [30], possibly indicative of different ecological niches. B. weihaiensis has been isolated from macroalgae and hence regularly encounters alginate from cell walls, whereas A. macleodii is rarely found on macrophytes and may primarily target storage laminarin released by exudation or decay.

The biphasic phenotype resembled sequential polysaccharide degradation through catabolite repression in human gut microbiota [25, 81, 82]. Related candidate genes in A. macleodii include CreA (Alt831_00877), two putative cAMP receptors (02509/03405), a partial phosphoenolpyruvate phosphotransferase system (01559) and one hybrid two-component system (02433), but none with differential expression between growth phases. Although this indicates a different mode of catabolite repression than in other 
a

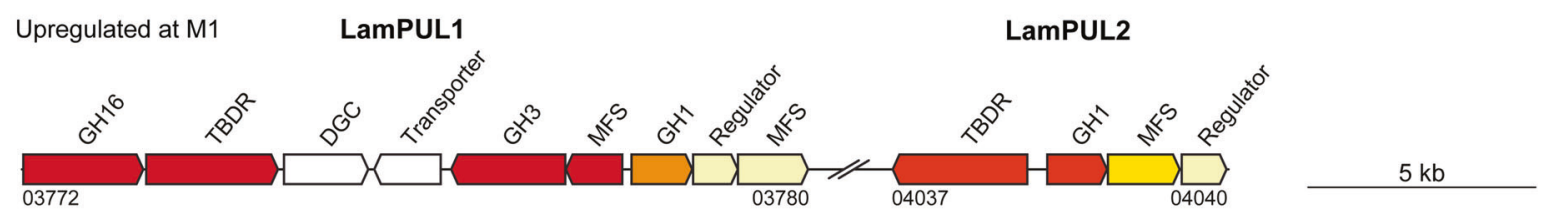

Upregulated at M2

PecPUL1

PecPUL2
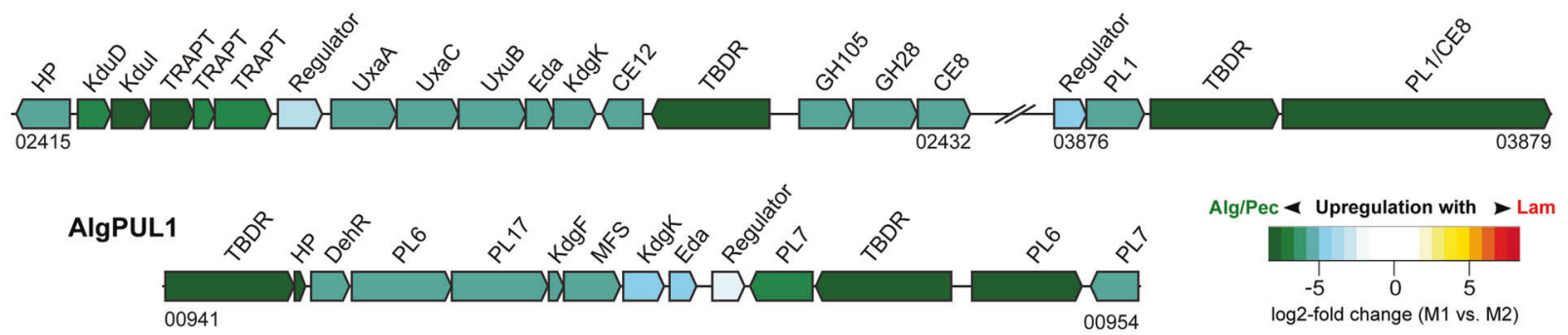

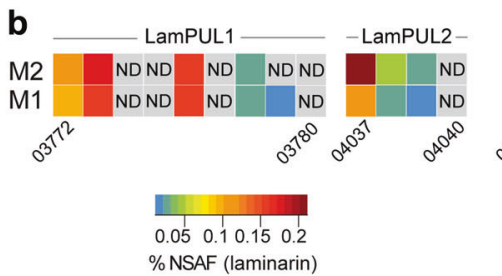

Fig. 2 Temporal changes in the expression of PUL for laminarin, alginate and pectin degradation. a Upregulation of genes during laminarin (phase M1; yellow/red colors) and alginate/pectin degradation (phase M2; blue/green colors) based on three biological replicates per sample (average $\log 2$-fold changes $\geq|2| ; P_{\text {adj }}<0.001$ ). b Corresponding abundances of proteins (\%NSAF; note the different scales for laminarin vs. alginate/pectin-related proteins). PUL encode CAZymes (PL polysaccharide lyase, GH glycoside hydrolase, CE carbohydrate esterase; numbers designating CAZyme families), transporters (TBDR TonBdependent receptor, MFS major facilitator superfamily transporter,

marine bacteria [83-85], the detection of all candidate genes in metatranscriptomes from the Atlantic, Pacific and Indian Oceans indicated that substrate-controlled gene expression influences the ecophysiology of Alteromonas. This notion was supported by detection of all transcripts near the original isolation site of strain 83-1 (Table S4). Substrate specialization can provide a competitive advantage in natural communities, but also promotes niche partitioning and the stable co-existence of bacterial taxa $[29,86]$.

\section{Cellular adaptations during sequential degradation of polysaccharides}

\section{Laminarin utilization (phase M1)}

Exponential growth during laminarin utilization was accompanied by upregulation of 253 genes compared to phase M2. Genes encoding laminarin hydrolases, including GH16, GH1 and GH3 located in LamPUL1 and LamPUL2, were among the highest upregulated genes (Figs. 2, 3; Table S3). The colocalization of GH16- and GH3-encoding genes resembles PUL organization in marine Bacteroidetes $[9,16]$, whereas

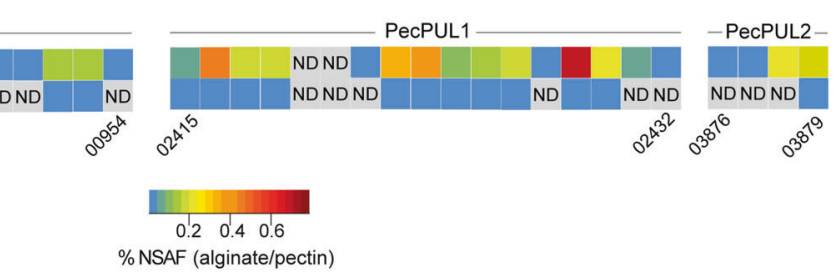

TRAPT tripartite ATP-independent transporter) and monomer utilization genes (DehR 4-deoxy-L-erythro-5-hexoseulose uronate reductase, Eda 2-keto-3-deoxy-6-phosphogluconate aldolase, KdgF protein for uronate linearization, KdgK 2-keto-3-deoxy-D-gluconate kinase, KduD 2-deoxy-D-gluconate 3-dehydrogenase, KduI 4-deoxy-L-threo-5-hexosulose-uronate ketol-isomerase, UxaA altronate dehydratase, UxaC glucuronate isomerase, $\mathrm{UxuB}$ fructuronate reductase). Numbers below PUL correspond to IMG locus tags (prefix Alt831_ omitted). DGC diguanylate cyclase, HP protein of unknown function, ND not detected, $\%$ NSAF normalized spectral abundance factor

that of GH16 and GH1 is reminiscent of Bacillus [30]. Homology with biochemically characterized endolytic $\beta$ (1-3)-glucanases (Fig. S3A) [63, 87] in combination with the spectrometric detection of several laminarin oligomers (Fig. S3B) suggested endolytic activity of the predicted GH16 (Alt831_03772). The exclusive upregulation of LamPUL1 and LamPUL2 with laminarin but not glucose indicated finetuned sensing of polymeric vs. monomeric glucose, comparable to Gramella forsetii [16]. In this context, only laminarin induced the upregulation of gene cluster Alt831_00338-47 (Table S3) encoding three xylose/glucose isomerases, two glucose oxidoreductases and a gluconate 2-dehydrogenase, suggesting that only polymeric glucose is partially channeled into oxidative degradation to generate additional reducing equivalents [88].

\section{Alginate/pectin utilization (phase M2)}

The switch to alginate/pectin utilization was mirrored by induction of the respective degradation pathways (Figs. 2, 3), with 290 upregulated genes compared to M1 and an enrichment of alginate/pectin-related proteins (Fig. S2B). 


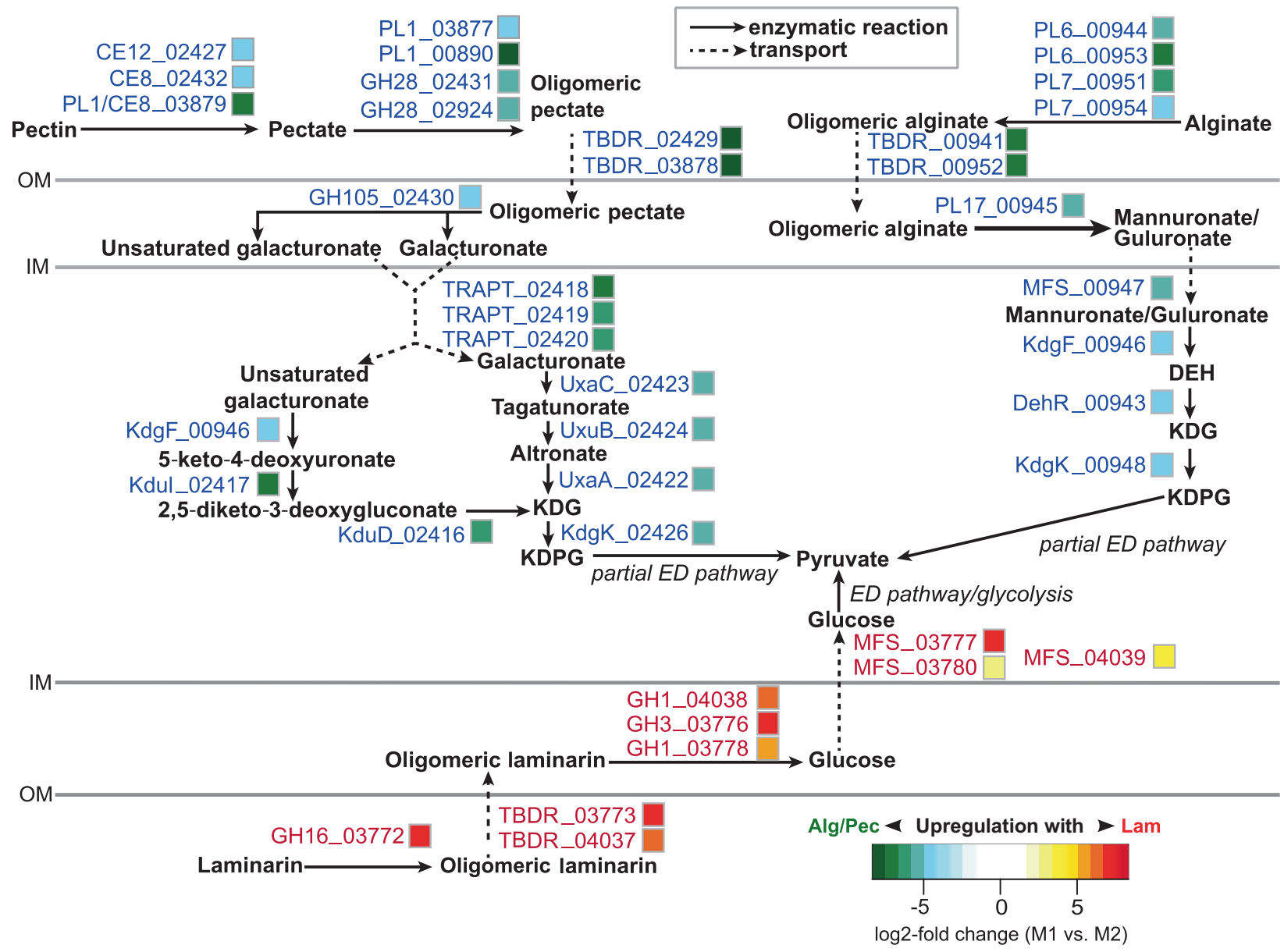

Fig. 3 Gene expression of metabolic pathways related to laminarin, alginate and pectin. Upregulation during laminarin (phase M1; yellow/ red colors) and alginate/pectin degradation (phase M2; blue/green colors) based on three biological replicates per sample (average log2fold change $\geq 121 ; P_{\text {adj }}<0.001$ ). Degradation via central intermediates (DEH 4-deoxy-L-erythro-5-hexoseulose uronate, KDG 2-keto-3deoxy-D-gluconate, KDGP 2-keto-3-deoxy-6-phosphogluconate) is related to CAZymes (PL polysaccharide lyase, GH glycoside hydrolase, CE carbohydrate esterase; with numbers designating CAZyme families), transporters (TBDR TonB-dependent receptor, MFS major

Pectin degradation was related to three genomic loci. PecPUL1 only encodes enzymes for processing pectin intermediates, whereas the three PL1 enzymes for initial hydrolysis are encoded separately: two in a second PUL (PecPUL2) and one distantly without adjacent CAZymes (Alt831_00890). Although our sampling procedure cannot exclude some carry-over between intra- and extracellular protein fractions, PL1_00890 was enriched 25-fold in the culture supernatant and hence likely secreted (Table S5). Similarities to the extracellular AlyA1 of Z. galactanivorans, which is likewise not inside a PUL and essential for attacking alginate gels and cell walls [89], indicate comparable roles as extracellular actors towards complex matrices of gelling polysaccharides. However, the effectivity of PL1_00890 may be limited by missing a CBM, as facilitator superfamily transporter, TRAPT tripartite ATP-independent transporter) and monomer utilization genes (DehR DEH reductase, $\mathrm{KdgF}$ protein for uronate linearization, KdgK KDG kinase, KduD 2-deoxy-D-gluconate 3-dehydrogenase, KduI 4-deoxy-L-threo-5-hexosulose-uronate ketol-isomerase, UxaA altronate dehydratase, UxaC glucuronate isomerase, $\mathrm{UxuB}$ fructuronate reductase). Enzyme names and IMG locus tags of encoding genes (separated by underscore; prefix Alt831_omitted) are shown next to each step. ED Entner-Doudoroff pathway, IM inner membrane, OM outer membrane

present in the otherwise homologous PelB pectate lyase of Pseudoalteromonas haloplanktis [49]. Pectin degradation is most likely regulated comparably via a LacI type repressor encoded in PecPUL1 and associated palindromic binding motif TGCCACCGGTGGCA upstream of genes encoding KduD, UxaA and GH28 (PecPUL1), a TonB-dependent receptor (PecPUL2) and a distant GH28 (Alt831_02924), respectively. Additional binding motifs with one mismatch were identified upstream of genes encoding the separate PL1, the GH105 in PecPUL1 and the transcriptional regulator in PecPUL2, respectively. An ecological relevance of pectin degradation has been supported by micromolar galacturonate concentrations during phytoplankton blooms, which positively correlated with abundances of Gammaproteobacteria [50]. 
Alginate degradation was related to AlgPUL1, which has been characterized in detail before [33]. The enzyme KdgF (Alt831_00946) essential for both pectin and alginate degradation [90] is encoded in AlgPUL1 and hence potentially shared by both pathways. In contrast, both pathways possess a dedicated KdgK enzyme comparable to Saccharophagus degradans [91]. Despite the significant upregulation in phase $\mathrm{M} 2$, proteomic detection of several AlgPUL1 enzymes in M1 (e.g., PL6 but not PL7 alginate lyases) indicated that induction of alginolytic systems started earlier, possibly yielding the accumulation of oligomers before their consumption in M2.

Missing net growth in phase M2 was surprising, as A. macleodii 83-1 grows exponentially on alginate/pectin when inoculated freshly (Fig. S4). Bacteriostasis from accumulation of KDPG, the key intermediate from both pathways, was hence unlikely [92]. We can also disregard growth-repressive $\mathrm{pH}$ changes during laminarin utilization, as laminarin supports growth at even higher concentrations (Fig. S4). One possible scenario is an initiation of maintenance metabolism [93] reflected by the upregulation of isocitrate lyase, a central enzyme in the glyoxylate shunt and mediator of slow growth [94]. Potential fermentative processes cannot be assessed, as putative inhibitory fermentation products (e.g., acetate) were outside the analytical window of FT-ICR-MS. The missing upregulation of flagellar synthesis (Alt831_01034-58/ 01083-01107), chemotaxis (00310-00315) and oxidative stress response (e.g., 00915/01232/02447) compared to glucose-grown stationary cells (Table $\mathrm{S} 1$ ) showed that M2 was no stationary phase and that processes related to exploitation of new niches were less expressed. This persistence-like but metabolically active phenotype [95] may provide adaptation to changing nutrient regimes and benefit the survivability of Alteromonas in the oceans.

\section{Ecological implications}

\section{Exometabolome diversity}

Laminarin and alginate/pectin utilization coincided with major changes in exometabolome composition, with 138 and 143 molecular masses unique to phases M1 vs. M2, respectively (Fig. 4a) and a decreasing relative fraction of phosphorous and oxygen among exometabolites (Table S2). The production of specific exometabolites with different polysaccharides likely influences chemical interactions with other bacteria [96]. A particular example is pyrroloquinoline quinone (PQQ), whose molecular mass (329.00522 Da) was exclusively detected at the end of phase M2 coincident with induction of the PQQ biosynthetic operon (Tables S2-S3). Identification of PQQ was corroborated by MS/MS fragmentation, yielding three fragment ions (285.016030, 241.026120 and 197.036170 Da) corresponding to loss of
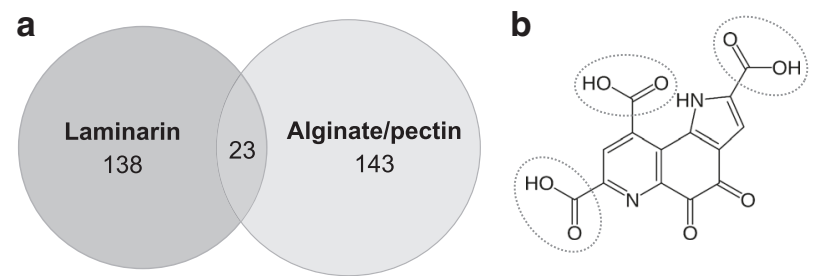

Fig. 4 Exometabolome analyses by FT-ICR-MS. a Number of molecular masses exclusively detected during laminarin and alginate/pectin utilization. b Structure of pyrroloquinoline quinone, with carboxylic groups with $\mathrm{CO}_{2}$ losses in MS/MS fragmentation encircled

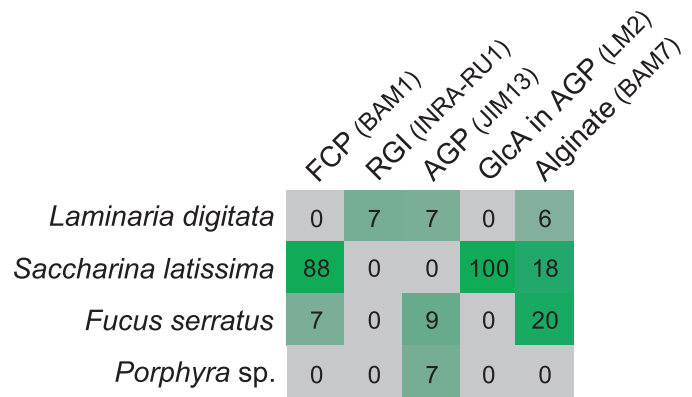

Fig. 5 Exudation of polysaccharide mixtures by macroalgae. Mean spot signal intensities in carbohydrate microarrays of four macroalgal exudates, only showing those of the 28 polysaccharide-specific probes with a positive signal (name indicated in parentheses; see Supplementary Methods). FCP fucose-containing polysaccharide, RGI rhamnogalacturonan I, AGP arabinogalactan-protein glycan, GlcA glucuronic acid

one, two and three $\mathrm{CO}_{2}$ (Fig. 4b). PQQ likely served as cofactor for alcohol dehydrogenases (ADHs) to convert methanol released during pectin deesterification, mirrored by upregulation of an adjacent PQQ-dependent ADH and other ADHs (Table S3). However, the further metabolic fate of methanol remains unclear. One possible route is oxidation to formate, but methylenetetrahydrofolate dehydrogenase (Alt831_02739) was not upregulated in M2. Missing growth on methanol as sole energy source (data not shown) and the absence of relevant genes also question potential assimilation via the serine cycle, although a recent study has suggested methylotrophy for a closely related $A$. macleodii [41]. Nonetheless, PQQ-/methanol-related traits may play a role in microbial interactions [97], as methanol is secreted by marine phytoplankton [98] and one mediator of A. macleodii interactions with cyanobacteria [41]. The fact that Alteromonas genomes vary in their content of PQQ-dependent ADHs (Table S6) indicates different ecological strategies related to alcohol metabolism.

\section{Cellular adaptations in light of polysaccharide release by macroalgae}

Using carbohydrate microarrays, we demonstrated release of polysaccharide mixtures by natural brown and red macroalgae, suggesting that cellular adaptations as found in $A$. macleodii 83-1 are environmentally relevant. Four of six 


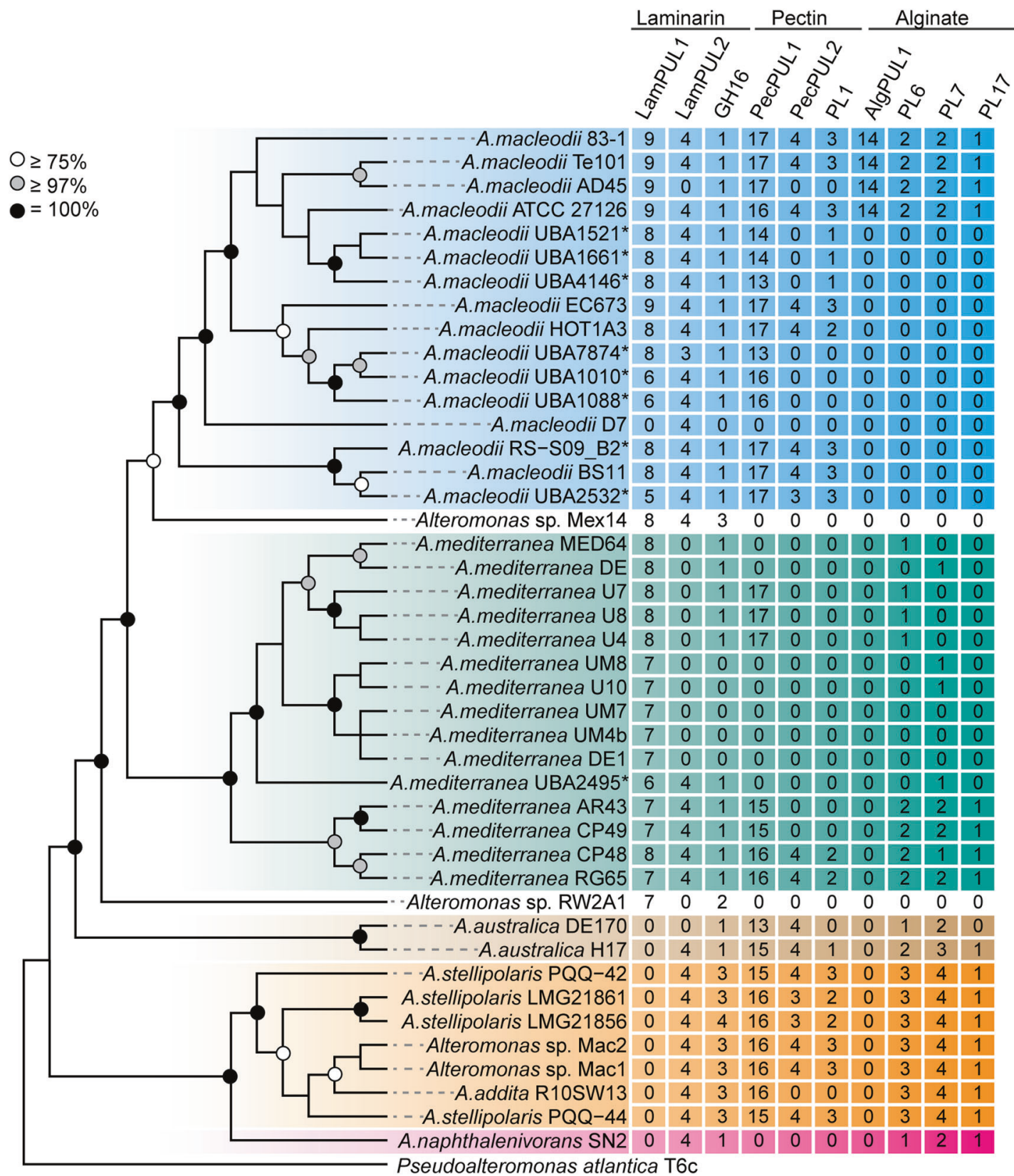

Fig. 6 Distribution and abundance of CAZymes among Alteromonas in relation to phylogeny. Numbers correspond to gene count in syntenic PUL compared to A. macleodii 83-1. In addition, total numbers of CAZymes for laminarin (GH16), pectin (PL1) and alginate degradation (PL6/7/17) are listed separately, as some are encoded outside of
PUL. Tree bases on alignment of 20 core proteins with Pseudoalteromonas atlantica T6c as outgroup (branch support values indicated by circles). Genomes shaded blue: A. macleodii; green: A. mediterranea; brown/yellow/pink/white: other Alteromonas. Asterisks indicate metagenome-assembled genomes algal species, in particular the brown algae Saccharina latissima and Fucus serratus, released varying levels of fucoidan, arabinogalactan, rhamnogalacturonan and alginate (Fig. 5), highlighting the ecological relevance of our cultivation experiment. S. latissima, $F$. serratus and related species are dominant macroalgae in temperate rocky habitats, with a global standing stock of 200 million tons [99] of which $>50 \%$ can be polysaccharides [100]. Hence, polysaccharides released by these algae may contribute sizably to secondary production in coastal zones worldwide. The detection of rhamnogalacturonan supports the notion that pectinous compounds are present in marine algae and that cellular adaptations thereto play an ecological role. The detection of released alginate is important in view of polysaccharide microhabitats, as dissolved alginate selfassembles into microgels that are rapidly colonized by marine bacteria, including A. macleodii [34]. Whereas commonly applied hydrolysis techniques only allow 
indirect conclusions on the native polymers, our method provides direct insights into the composition of macroalgaederived polysaccharide mixtures.

\section{Potential for polysaccharide mixture utilization among Alteromonas spp.}

To broadly assess the predisposition towards polysaccharide mixtures, we compared CAZyme content of A. macleodii 83-1 with 33 closed and 9 metagenome-assembled Alteromonas genomes (Table S7) from diverse marine regions $[101,102]$. Presence of the complete PUL repertoire in $A$. macleodii strains ATCC27126 $6^{\mathrm{T}}, \mathrm{Te} 101$ and AD45 isolated from distant locations (Fig. 6) indicated that polysaccharide mixture utilization is relevant in different habitats. Missing PUL expression in Te101 during co-culture with nitrogenfixing Trichodesmium cyanobacteria [70] underlined that PUL are substrate regulated, and furthermore showed that polysaccharides are rarely secreted by healthy Trichodesmium. However, increasing TEP production when Trichodesmium blooms demise [103] indicates that polysaccharide-related traits may become important at other stages of their interaction.

The wide occurrence of laminarin-related genes highlights the importance of laminarin as bacterial substrate [45]. Homologs of the GH16 were found in $>85 \%$ of Alteromonas genomes, but not all possessing both complete laminarin PUL (Fig. 6). Due to the broad substrate ranges of CAZyme families such as GH16, some homologs may however target other polysaccharides. For instance, A. stellipolaris, A. addita and strains Mac1/Mac2 encode a second GH16 with 99\% sequence similarity to a $\beta$-agarase [104], probably opening further 'substrate niches' during degradation of algal biomass.

The occurrence of pectin-related CAZymes in Alteromonas and Pseudoalteromonas [49] supports the notion that pectinous substrates are indeed ecologically relevant in marine systems. Over $80 \%$ of Alteromonas genomes possess homologs of PecPUL1 enabling the metabolism of pectin oligomers, but PL1 enzymes needed for initial polymer hydrolysis are often absent. Consequently, strains like A. mediterranea $\mathrm{U} 7$ are unable to grow on polymeric pectin (Fig. S5) but may scavenge pectin oligomers from PL1-encoding strains, being reminiscent of interactions between pioneers, harvesters and scavengers [105]. A similar scenario may apply to alginate degradation. Whereas only four strains harbor the complete AlgPUL1, other Alteromonas spp. possess alginate lyases as well, which are clustered within two PUL (A. stellipolaris), in one PUL plus additional scattered lyases (A. australica) or completely dispersed (A. mediterranea). These genomic differences may influence alginolytic potentials and contribute to ecological speciation, as seen in alginolytic vibrios [105]. The observed microdiversity in enzymatic features, sometimes in strains from distant locations and habitats (e.g., subclade BS11, RS-S09 and UBA2532), indicates different 'carbohydrate utilization ecotypes ' among Alteromonas adapted to distinct substrate niches [106, 107].

\section{Conclusions}

Although being a simplified approximation to processes in natural habitats, the demonstrated bacterial adaptations to polysaccharide mixtures provide a window into organismal and functional dynamics associated with successive 'polysaccharide niches' during phytoplankton blooms [21, 22] where bacteria with varying hydrolytic potentials and substrate preferences compete. Together with the shown release of polysaccharide mixtures by macroalgae and the genomic predisposition of Alteromonas towards such mixtures, we provide comprehensive cellular and environmental perspectives on the recycling of algal biomass, a key step in marine carbon cycling. Considering the substantial abundance and primary productivity of micro- and macroalgae, these insights are relevant for carbon fluxes and bacteria-algae interactions in the oceans.

\section{Data accessibility}

The closed and annotated genome of A. macleodii 83-1 is publicly available under IMG accession \#2716884210. Raw transcriptomic reads from all biological replicates have been deposited at the Gene Expression Omnibus under GSE107306. Proteomics data from all biological replicates have been deposited to the ProteomeXchange Consortium via PRIDE [80] under PXD008280. The complete FT-ICR-MS data are shown in Table S2.

Acknowledgements We gratefully acknowledge technical assistance by Rolf Weinert (HPLC), Katrin Klaproth, Maren Zark, Helena Osterholz and Jutta Niggemann (FT-ICR-MS), Sebastian Grund, Frank Unfried and Stephanie Markert (proteomics), and Cathrin Spröer (genome sequencing). The Biological Institute Helgoland of the Alfred Wegener Institute, in particular Antje Wichels, Eva-Maria Brodte, Gunnar Gerdts and Uwe Nettelmann, are thanked for excellent scientific support. RNA sequencing was expertly performed by the Earlham Institute (Norwich, UK). This work was funded by the German Research Foundation (DFG) through grants WI3888/1-2 (to MW), SCHW595/9-1 (to TS), the Emmy Noether program (to J-HH) and the Collaborative Research Centre TRR51. HK was supported by Volkswagen Foundation under VW-Vorab grant 'Marine Biodiversity across Scales' (MarBAS; ZN3112).

\section{Compliance with ethical standards}

Conflict of interest The authors declare that they have no conflict of interest. 


\section{References}

1. Kraan S. Algal polysaccharides, novel applications and outlook. In: Chang C-F, editor. Carbohydrates - comprehensive studies on glycobiology and glycotechnology. Rijeka: InTech; 2012. p. 489-532.

2. Rossi F, De Philippis R. Exocellular polysaccharides in microalgae and cyanobacteria: chemical features, role and enzymes and genes involved in their biosynthesis. The physiology of microalgae. Eds. Borowitzka MA, Beardall J, Raven JA. Cham: Springer International Publishing; 2016. p. 565-90.

3. Fletcher HR, Biller P, Ross AB, Adams JMM. The seasonal variation of fucoidan within three species of brown macroalgae. Algal Res. 2017;22:79-86.

4. Thornton DCO. Dissolved organic matter (DOM) release by phytoplankton in the contemporary and future ocean. Eur $\mathbf{J}$ Phycol. 2014;49:20-46.

5. Hehemann J-H, Boraston AB, Czjzek M. A sweet new wave: structures and mechanisms of enzymes that digest polysaccharides from marine algae. Curr Opin Struct Biol. 2014;28:77-86.

6. Lombard V, Golaconda Ramulu H, Drula E, Coutinho PM, Henrissat B. The carbohydrate-active enzymes database (CAZy) in 2013. Nucleic Acids Res. 2014;42:D490-5.

7. Michel G, Czjzek M. Polysaccharide-degrading enzymes from marine bacteria. In: Trincone A, editor. Marine Enzymes for Biocatalysis. Cambridge: Woodhead Publishing; 2013. p. 429-64.

8. Fernández-Gómez B, Richter M, Schüler M, Pinhassi J, Acinas SG, González JM, et al. Ecology of marine Bacteroidetes: a comparative genomics approach. ISME J. 2013;7:1026-37.

9. Bennke CM, Krüger K, Kappelmann L, Huang S, Gobet A, Schüler M, et al. Polysaccharide utilisation loci of Bacteroidetes from two contrasting open ocean sites in the North Atlantic. Environ Microbiol. 2016;18:4456-70.

10. Weiner RM, Taylor LE, Henrissat B, Hauser L, Land M, Coutinho PM, et al. Complete genome sequence of the complex carbohydrate-degrading marine bacterium, Saccharophagus degradans strain 2-40T. PLoS Genet. 2008;4:e1000087.

11. Martinez-Garcia M, Brazel DM, Swan BK, Arnosti C, Chain PSG, Reitenga KG, et al. Capturing single cell genomes of active polysaccharide degraders: an unexpected contribution of Verrucomicrobia. PLoS ONE. 2012;7:e35314.

12. Lage OM, Bondoso J. Planctomycetes and macroalgae, a striking association. Front Microbiol. 2014;5:267.

13. Grondin JM, Tamura K, Déjean G, Abbott DW, Brumer H. Polysaccharide utilization loci: fueling microbial communities. J Bacteriol. 2017;199:e00860-16.

14. Barbeyron T, Thomas F, Barbe V, Teeling H, Schenowitz C, Dossat $\mathrm{C}$, et al. Habitat and taxon as driving forces of carbohydrate catabolism in marine heterotrophic bacteria: example of the model algae-associated bacterium Zobellia galactanivorans $\mathrm{Dsij}^{\mathrm{T}}$. Environ Microbiol. 2016;18:4610-27.

15. Ficko-Blean E, Préchoux A, Thomas F, Rochat T, Larocque R, Zhu Y, et al. Carrageenan catabolism is encoded by a complex regulon in marine heterotrophic bacteria. Nat Commun. 2017; 8:1685.

16. Kabisch A, Otto A, König S, Becher D, Albrecht D, Schüler M, et al. Functional characterization of polysaccharide utilization loci in the marine Bacteroidetes 'Gramella forsetii' KT0803. ISME J. 2014;8:1492-502.

17. Tang K, Lin Y, Han Y, Jiao N. Characterization of potential polysaccharide utilization systems in the marine Bacteroidetes Gramella flava JLT2011 using a multi-omics approach. Front Microbiol. 2017;8:220.

18. Thomas F, Barbeyron T, Tonon T, Génicot S, Czjzek M, Michel G. Characterization of the first alginolytic operons in a marine bacterium: from their emergence in marine Flavobacteriia to their independent transfers to marine Proteobacteria and human gut Bacteroides. Environ Microbiol. 2012;14:2379-94.

19. Xing P, Hahnke RL, Unfried F, Markert S, Huang S, Barbeyron $\mathrm{T}$, et al. Niches of two polysaccharide-degrading Polaribacter isolates from the North Sea during a spring diatom bloom. ISME J. 2015;9:1410-22.

20. Verdugo P, Alldredge AL, Azam F, Kirchman DL, Passow U, Santschi PH. The oceanic gel phase: a bridge in the DOM-POM continuum. Mar Chem. 2004;92:67-85.

21. Teeling H, Fuchs BM, Becher D, Klockow C, Gardebrecht A, Bennke CM, et al. Substrate-controlled succession of marine bacterioplankton populations induced by a phytoplankton bloom. Science. 2012;336:608-11.

22. Teeling H, Fuchs BM, Bennke CM, Krüger K, Chafee M, Kappelmann L, et al. Recurring patterns in bacterioplankton dynamics during coastal spring algae blooms. elife. 2016;5: e11888.

23. Nelson CE, Goldberg SJ, Wegley Kelly L, Haas AF, Smith JE, Rohwer F, et al. Coral and macroalgal exudates vary in neutral sugar composition and differentially enrich reef bacterioplankton lineages. ISME J. 2013;7:962-79.

24. Villacorte LO, Ekowati Y, Neu TR, Kleijn JM, Winters H, Amy $\mathrm{G}$, et al. Characterisation of algal organic matter produced by bloom-forming marine and freshwater algae. Water Res. 2015;73:216-30.

25. Rogers TE, Pudlo NA, Koropatkin NM, Bell JSK, Moya Balasch $\mathrm{M}$, Jasker K, et al. Dynamic responses of Bacteroides thetaiotaomicron during growth on glycan mixtures. Mol Microbiol. 2013;88:876-90.

26. Schwalm ND, Townsend GE, Groisman EA. Prioritization of polysaccharide utilization and control of regulator activation in Bacteroides thetaiotaomicron. Mol Microbiol. 2017;104:32-45.

27. Tuncil YE, Xiao Y, Porter NT, Reuhs BL, Martens EC, Hamaker BR. Reciprocal prioritization to dietary glycans by gut bacteria in a competitive environment promotes stable coexistence. mBio. 2017;8:e01068-17.

28. Cuskin F, Lowe EC, Temple MJ, Zhu Y, Cameron EA, Pudlo NA, et al. Human gut Bacteroidetes can utilize yeast mannan through a selfish mechanism. Nature. 2015;517:165-9.

29. Goyal A, Dubinkina V, Maslov S. Microbial community structure predicted by the stable marriage problem. Preprint at http://a rxiv.org/abs/1712.06042 (2017). Accessed 12 Apr 2018).

30. Zhu Y, Chen P, Bao Y, Men Y, Zeng Y, Yang J, et al. Complete genome sequence and transcriptomic analysis of a novel marine strain Bacillus weihaiensis reveals the mechanism of brown algae degradation. Sci Rep. 2016;6:38248.

31. Thomas F, Bordron P, Eveillard D, Michel G. Gene expression analysis of Zobellia galactanivorans during the degradation of algal polysaccharides reveals both substrate-specific and shared transcriptome-wide responses. Front Microbiol. 2017;8:1808.

32. Reintjes G, Arnosti C, Fuchs BM, Amann R. An alternative polysaccharide uptake mechanism of marine bacteria. ISME J. 2017;11:1640-50.

33. Neumann AM, Balmonte JP, Berger M, Giebel H-A, Arnosti C, Brinkhoff T, et al. Different utilization of alginate and other algal polysaccharides by marine Alteromonas macleodii ecotypes. Environ Microbiol. 2015;17:3857-68.

34. Mitulla M, Dinasquet J, Guillemette R, Simon M, Azam F, Wietz M. Response of bacterial communities from California coastal waters to alginate particles and an alginolytic Alteromonas macleodii strain. Environ Microbiol. 2016;18:4369-77.

35. Taylor JD, Cunliffe M. Coastal bacterioplankton community response to diatom-derived polysaccharide microgels. Environ Microbiol Rep. 2017;9:151-7. 
36. Wietz M, Wemheuer B, Simon H, Giebel H-A, Seibt MA, Daniel $\mathrm{R}$, et al. Bacterial community dynamics during polysaccharide degradation at contrasting sites in the Southern and Atlantic Oceans. Environ Microbiol. 2015;17:3822-31.

37. Ivars-Martínez E, D'Auria G, Rodríguez-Valera F, SánchezPorro C, Ventosa A, Joint I, et al. Biogeography of the ubiquitous marine bacterium Alteromonas macleodii determined by multilocus sequence analysis. Mol Ecol. 2008;17:4092-106.

38. Diner RE, Schwenck SM, McCrow JP, Zheng H, Allen AE. Genetic manipulation of competition for nitrate between heterotrophic bacteria and diatoms. Front Microbiol. 2016;7:880.

39. Wu S, Zhou J, Xin Y, Xue S. Nutritional stress effects under different nitrogen sources on the genes in microalga Isochrysis zhangjiangensis and the assistance of Alteromonas macleodii in releasing the stress of amino acid deficiency. J Phycol. 2015;51:885-95.

40. Aharonovich D, Sher D. Transcriptional response of Prochlorococcus to co-culture with a marine Alteromonas: differences between strains and the involvement of putative infochemicals. ISME J. 2016;10:2892-906.

41. Lee MD, Walworth NG, McParland EL, Fu F-X, Mincer TJ, Levine NM, et al. The Trichodesmium consortium: conserved heterotrophic co-occurrence and genomic signatures of potential interactions. ISME J. 2017;11:1813-24.

42. Morris JJ, Johnson ZI, Szul MJ, Keller M, Zinser ER. Dependence of the cyanobacterium Prochlorococcus on hydrogen peroxide scavenging microbes for growth at the ocean's surface. PLoS ONE. 2011;6:e16805.

43. Beattie A, Hirst EL, Percival E. Studies on the metabolism of the Chrysophyceae. Comparative structural investigations on leucosin (chrysolaminarin) separated from diatoms and laminarin from the brown algae. Biochem J. 1961;79:531-7.

44. Becker S, Scheffel A, Polz MF, Hehemann J-H. Accurate quantification of laminarin in marine organic matter with enzymes from marine microbes. Appl Environ Microbiol. 2017;83:e03389-16.

45. Arnosti C, Steen AD, Ziervogel K, Ghobrial S, Jeffrey WH. Latitudinal gradients in degradation of marine dissolved organic carbon. PLoS ONE. 2011;6:e28900.

46. Planas A. Bacterial 1,3-1,4- $\beta$-glucanases: structure, function and protein engineering. Biochim Biophys Acta. 2000;1543:361-82.

47. Davis TA, Volesky B, Mucci A. A review of the biochemistry of heavy metal biosorption by brown algae. Water Res. 2003;37:4311-30.

48. Ertesvåg H. Alginate-modifying enzymes: biological roles and biotechnological uses. Front Microbiol. 2015;6:523.

49. Hehemann J-H, Truong L Van, Unfried F, Welsch N, Kabisch J, Heiden SE. et al. Aquatic adaptation of a laterally acquired pectin degradation pathway in marine gammaproteobacteria. Environ Microbiol. 2017;19:2320-33.

50. Sperling M, Piontek J, Engel A, Wiltshire KH, Niggemann J, Gerdts G, et al. Combined carbohydrates support rich communities of particle-associated marine bacterioplankton. Front Microbiol. 2017;08:65.

51. Passow U. Transparent exopolymer particles (TEP) in aquatic environments. Prog Oceanogr. 2002;55:287-333.

52. Duarte CM, Cebrián J. The fate of marine autotrophic production. Limnol Oceanogr. 1996;41:1758-66.

53. Steneck RS, Graham MH, Bourque BJ, Corbett D, Erlandson JM, Estes JA, et al. Kelp forest ecosystems: biodiversity, stability, resilience and future. Environ Conserv. 2003;29:436-59.

54. Benner R, Pakulski J, McCarthy M, Hedges J, Hatcher P. Bulk chemical characteristics of dissolved organic matter in the ocean. Science. 1992;255:1561-4

55. Zech H, Thole S, Schreiber K, Kalhöfer D, Voget S, Brinkhoff T, et al. Growth phase-dependent global protein and metabolite profiles of Phaeobacter gallaeciensis strain DSM 17395, a member of the marine Roseobacter-clade. Proteomics. 2009;9:3677-97.

56. Hahnke S, Brock NL, Zell C, Simon M, Dickschat JS, Brinkhoff T. Physiological diversity of Roseobacter clade bacteria cooccurring during a phytoplankton bloom in the North Sea. Syst Appl Microbiol. 2013;36:39-48.

57. Mopper K, Schultz CA, Chevolot L, Germain C, Revuelta R, Dawson R. Determination of sugars in unconcentrated seawater and other natural waters by liquid chromatography and pulsed amperometric detection. Environ Sci Technol. 1992;26:133-8.

58. Yin Y, Mao X, Yang J, Chen X, Mao F, Xu Y. dbCAN: a web resource for automated carbohydrate-active enzyme annotation. Nucleic Acids Res. 2012;40:W445-51.

59. Finn RD, Clements J, Arndt W, Miller BL, Wheeler TJ, Schreiber F, et al. HMMER web server: 2015 update. Nucleic Acids Res. 2015;43:W30-8.

60. Saier MH, Reddy VS, Tsu BV, Ahmed MS, Li C, MorenoHagelsieb G. The Transporter Classification Database (TCDB): recent advances. Nucleic Acids Res. 2016,44:D372-9.

61. Finn R, Attwood TK, Babbitt PC, Bateman A, Bork P, Bridge AJ, et al. InterPro in 2017 - beyond protein family and domain annotations. Nucleic Acids Res. 2017,45:D190-9.

62. Robert X, Gouet P. Deciphering key features in protein structures with the new ENDscript server. Nucleic Acids Res. 2014;42: W320-4.

63. Labourel A, Jam M, Jeudy A, Hehemann J-H, Czjzek M, Michel $\mathrm{G}$. The $\beta$-glucanase ZgLamA from Zobellia galactanivorans evolved a bent active site adapted for efficient degradation of algal laminarin. J Biol Chem. 2014;289:2027-42.

64. Love MI, Huber W, Anders S. Moderated estimation of fold change and dispersion for RNA-seq data with DESeq2. Genome Biol. 2014;15:550.

65. Zybailov B, Mosley AL, Sardiu ME, Coleman MK, Florens L, Washburn MP. Statistical analysis of membrane proteome expression changes in Saccharomyces cerevisiae. J Proteome Res. 2006;5:2339-47.

66. Dittmar T, Koch B, Hertkorn N, Kattner G. A simple and efficient method for the solid-phase extraction of dissolved organic matter (SPE-DOM) from seawater. Limnol Oceanogr Methods. 2008;6:230-5.

67. Seidel M, Beck M, Riedel T, Waska H, Suryaputra IGNA, Schnetger B, et al. Biogeochemistry of dissolved organic matter in an anoxic intertidal creek bank. Geochim Cosmochim Acta. 2014;140:418-34.

68. Vidal-Melgosa S, Pedersen HL, Schückel J, Arnal G, Dumon C, Amby DB, et al. A new versatile microarray-based method for high throughput screening of carbohydrate-active enzymes. J Biol Chem. 2015;290:9020-36.

69. Seemann T. Prokka: rapid prokaryotic genome annotation. Bioinformatics. 2014;30:2068-9.

70. Hou S, López-Pérez M, Pfreundt U, Belkin N, Stüber K, Huettel $\mathrm{B}$, et al. Benefit from decline: the primary transcriptome of Alteromonas macleodii str. Te101 during Trichodesmium demise. ISME J. 2018;12:981-96.

71. Ivars-Martinez E, Martin-Cuadrado A-B, D'Auria G, Mira A, Ferriera S, Johnson J, et al. Comparative genomics of two ecotypes of the marine planktonic copiotroph Alteromonas macleodii suggests alternative lifestyles associated with different kinds of particulate organic matter. ISME J. 2008;2:1194-212.

72. López-Pérez M, Gonzaga A, Martin-Cuadrado A-B, Onyshchenko O, Ghavidel A, Ghai R, et al. Genomes of surface isolates of Alteromonas macleodii: the life of a widespread marine opportunistic copiotroph. Sci Rep. 2012;2:696.

73. López-Pérez M, Gonzaga A, Rodriguez-Valera F. Genomic diversity of 'deep ecotype' Alteromonas macleodii isolates: 
evidence for Pan-Mediterranean clonal frames. Genome Biol Evol. 2013;5:1220-32.

74. Chen I-MA, Markowitz VM, Chu K, Palaniappan K, Szeto E, Pillay $\mathrm{M}$, et al. IMG/M: integrated genome and metagenome comparative data analysis system. Nucleic Acids Res. 2017;45: D507-16.

75. Medema MH, Takano E, Breitling R. Detecting sequence homology at the gene cluster level with MultiGeneBlast. Mol Biol Evol. 2013;30:1218-23.

76. Chaudhari NM, Gupta VK, Dutta C. BPGA- an ultra-fast pangenome analysis pipeline. Sci Rep. 2016;6:24373.

77. Edgar RC. MUSCLE: multiple sequence alignment with high accuracy and high throughput. Nucleic Acids Res. 2004;32:1792-7.

78. Price MN, Dehal PS, Arkin AP. FastTree: computing large minimum evolution trees with profiles instead of a distance matrix. Mol Biol Evol. 2009;26:1641-50.

79. Miller M, Pfeiffer W, Schwartz T. (2010). Creating the CIPRES science gateway for inference of large phylogenetic trees. In: Proceedings of the Gateway Computing Environments Workshop. New Orleans: IEEE; 2010. p. 1-8. http://toc.proceedings. com/10226webtoc.pdf

80. Vizcaíno JA, Csordas A, del-Toro N, Dianes JA, Griss J, Lavidas I, et al. 2016 update of the PRIDE database and its related tools. Nucleic Acids Res. 2016;44:D447-56.

81. Görke B, Stülke J. Carbon catabolite repression in bacteria: many ways to make the most out of nutrients. Nat Rev Microbiol. 2008;6:613-24.

82. Lynch JB, Sonnenburg JL. Prioritization of a plant polysaccharide over a mucus carbohydrate is enforced by a Bacteroides hybrid two-component system. Mol Microbiol. 2012;85:478-91.

83. Blokesch M. Chitin colonization, chitin degradation and chitininduced natural competence of Vibrio cholerae are subject to catabolite repression. Environ Microbiol. 2012;14:1898-912.

84. Ensor LA, Stosz SK, Weiner RM. Expression of multiple complex polysaccharide-degrading enzyme systems by marine bacterium strain 2-40. J Ind Microbiol Biotechnol. 1999;23:123-6.

85. Furusawa G, Lau N-S, Suganthi A, Amirul AA-A. Agarolytic bacterium Persicobacter sp. CCB-QB2 exhibited a diauxic growth involving galactose utilization pathway. MicrobiologyOpen. 2017;6:e00405.

86. Baran R, Brodie EL, Mayberry-Lewis J, Hummel E, Da Rocha UN, Chakraborty R, et al. Exometabolite niche partitioning among sympatric soil bacteria. Nat Commun. 2015;6:8289.

87. Labourel A, Jam M, Legentil L, Sylla B, Hehemann J-H, Ferrières $\mathrm{V}$, et al. Structural and biochemical characterization of the laminarinase $\mathrm{Zg}$ LamC $_{\mathrm{GH} 16}$ from Zobellia galactanivorans suggests preferred recognition of branched laminarin. Acta Crystallogr Sect D Biol Crystallogr. 2015;71:173-84.

88. Buurman ET, ten Voorde GJ, Teixeira de Mattos MJ. The physiological function of periplasmic glucose oxidation in phosphate-limited chemostat cultures of Klebsiella pneumoniae NCTC 418. Microbiology. 1994;140:2451-8.

89. Zhu Y, Thomas F, Larocque R, Li N, Duffieux D, Cladière L, et al. Genetic analyses unravel the crucial role of a horizontally acquired alginate lyase for brown algal biomass degradation by Zobellia galactanivorans. Environ Microbiol. 2017;19:2164-81.

90. Hobbs JK, Lee SM, Robb M, Hof F, Barr C, Abe KT, et al. $\mathrm{KdgF}$, the missing link in the microbial metabolism of uronate sugars from pectin and alginate. Proc Natl Acad Sci USA. 2016;113:6188-93.
91. Takagi T, Morisaka H, Aburaya S, Tatsukami Y, Kuroda K, Ueda M. Putative alginate assimilation process of the marine bacterium Saccharophagus degradans 2-40 based on quantitative proteomic analysis. Mar Biotechnol. 2016;18:15-23.

92. Fuhrman LK, Wanken A, Nickerson KW, Conway T. Rapid accumulation of intracellular 2-keto-3-deoxy-6-phosphogluconate in an Entner-Doudoroff aldolase mutant results in bacteriostasis. FEMS Microbiol Lett. 1998;159:261-6.

93. van Bodegom P. Microbial maintenance: a critical review on its quantification. Microb Ecol. 2007;53:513-23.

94. Beste DJV, McFadden J. System-level strategies for studying the metabolism of Mycobacterium tuberculosis. Mol Biosyst. 2010;6:2363-72.

95. Haruta S, Kanno N. Survivability of microbes in natural environments and their ecological impacts. Microbes Environ. 2015;30:123-5.

96. Chodkowski JL, Shade A. A synthetic community system for probing microbial interactions driven by exometabolites. mSystems. 2017;2:e00129.

97. Toyama H. Pyrroloquinoline quinone (PQQ). Vandamme EJ, Revuelta JL. In: Industrial biotechnology of vitamins, biopigments, and antioxidants. Weinheim: Wiley-VCH; 2016. p. 367-88.

98. Mincer TJ, Aicher AC. Methanol production by a broad phylogenetic array of marine phytoplankton. PLOS ONE. 2016;11: e0150820.

99. Carpenter LJ, Liss PS. On temperate sources of bromoform and other reactive organic bromine gases. J Geophys Res Atmos. 2000;105:20539-47.

100. Mabeau S, Kloareg B. Isolation and analysis of the cell walls of brown algae: Fucus spiralis, F. ceranoides, F. vesiculosus, F. serratus, Bifurcaria bifurcata and Laminaria digitata. J Exp Bot. 1987;38:1573-80.

101. Haroon MF, Thompson LR, Parks DH, Hugenholtz P, Stingl U. A catalogue of 136 microbial draft genomes from Red Sea metagenomes. Sci Data. 2016;3:160050.

102. Parks DH, Rinke C, Chuvochina M, Chaumeil P-A, Woodcroft BJ, Evans PN, et al. Recovery of nearly 8,000 metagenomeassembled genomes substantially expands the tree of life. Nat Microbiol. 2017;2:1533-42.

103. Berman-Frank I, Rosenberg G, Levitan O, Haramaty L, Mari X. Coupling between autocatalytic cell death and transparent exopolymeric particle production in the marine cyanobacterium Trichodesmium. Environ Microbiol. 2007;9:1415-22.

104. Chi W-J, Park DY, Seo YB, Chang YK, Lee S-Y, Hong S-K. Cloning, expression, and biochemical characterization of a novel GH16 $\beta$-agarase AgaG1 from Alteromonas sp. GNUM-1. Appl Microbiol Biotechnol. 2014;98:4545-55.

105. Hehemann J-HH, Arevalo P, Datta MS, Yu X, Corzett $\mathrm{CH}$, Henschel A, et al. Adaptive radiation by waves of gene transfer leads to fine-scale resource partitioning in marine microbes. Nat Commun. 2016;7:12860.

106. Zimmerman AE, Martiny AC, Allison SD. Microdiversity of extracellular enzyme genes among sequenced prokaryotic genomes. ISME J. 2013;7:1187-99.

107. Sheridan PO, Martin JC, Lawley TD, Browne HP, Harris HMB, Bernalier-Donadille A, et al. Polysaccharide utilization loci and nutritional specialization in a dominant group of butyrateproducing human colonic Firmicutes. Microb Genom. 2016;2: e000043. 